\title{
El impacto de la competitividad política y la igualdad en la calidad de la democracia. El caso argentino (2003-2013)
}

\author{
NICOLÁS CHERNY \\ Doctor en Ciencias Sociales (FLACSO, Argentina) \\ Profesor de la Universidad de Buenos Aires \\ Buenos Aires, Argentina \\ ncherny@sociales.uba.ar
}

GERARDO SCHERLIS Doctor en Ciencia Política (Universidad de Leiden, Holanda) Profesor de la Universidad de Buenos Aires Buenos Aires, Argentina gscherlis@derecho.uba.ar

Resumen El propósito del artículo es analizar la calidad democrática en Argentina en el período 2003-2013. En primer lugar, describimos la evolución de los diferentes indicadores típicos de calidad democrática. La segunda parte observa el impacto de la variación en la competitividad política y la igualdad sobre tres dimensiones: estado de derecho, rendición de cuentas electoral y rendición de cuentas interinstitucional. Los hallazgos son consistentes con la literatura que sostiene que una disminución de la competitividad afecta negativamente la calidad de la democracia.Y sugieren que una mejora en los indicadores de igualdad podría favorecer bajo ciertas circunstancias un deterioro de la calidad democrática.

Palabras clave: Argentina; kirchnerismo; calidad democrática; competitividad; igualdad; accountability.

\section{Introducción}

$\mathrm{E}$ L PROPÓsito de eSte aRTí́culo es doble. Por un lado, realizar una Eevaluación de la calidad de la democracia en la Argentina contemporánea. Por otro, observar el impacto de la variación en los niveles de competitividad política e igualdad sobre otras tres dimensiones clave de la calidad democrática: Estado de derecho, rendición de cuentas electoral y rendición de cuentas interinstitucional. Para ello nos preguntamos, primero, en qué medida una variación en la competitividad política afecta la rendición de cuentas y el imperio de la ley.Y, segundo, qué efectos tiene un cambio en los indicadores de igualdad sobre las dimensiones procedimentales de la calidad de la democracia.

La perspectiva que adoptamos está basada en el marco analítico de Morlino $(2009 ; 2011)$ que definió y propuso observar y establecer relaciones entre ocho dimensiones de análisis de la democracia. El artículo se organiza de la siguiente manera: la segunda sección presenta y resume 
Tabla 1: Calidad democrática en Argentina, 2010

\begin{tabular}{|l|c|c|}
\hline \multicolumn{1}{|c|}{ Dimensión } & Promedio & Calidad \\
\hline Estado de derecho & 2,80 & Media hacia baja \\
\hline Rendición de cuentas electoral & 3,25 & Media \\
\hline Rendición de cuentas interinstitucional & 3,40 & Media hacia alta \\
\hline Participación política & 3,60 & Media hacia baja \\
\hline Competitividad política & 2,70 & Media hacia baja \\
\hline Responsividad & 2,50 & Media hacia alta \\
\hline Libertad & 3,80 & Media \\
\hline Igualdad & 3,20 & \\
\hline
\end{tabular}

Fuente: Novaro, 2010

Tabla 2: Estado de Derecho

\begin{tabular}{|c|c|c|c|c|}
\hline $\begin{array}{c}\text { Seguridad individual } \\
\text { y orden civil }\end{array}$ & $\begin{array}{c}\text { Independencia y } \\
\text { modernización } \\
\text { de la Justicia }\end{array}$ & $\begin{array}{c}\text { Capacidad } \\
\text { institucional y } \\
\text { administrativa }\end{array}$ & $\begin{array}{c}\text { Lucha contra } \\
\text { la corrupción }\end{array}$ & $\begin{array}{c}\text { Fuerzas de } \\
\text { seguridad bajo } \\
\text { tutela civil }\end{array}$ \\
\hline 4,00 & 3,00 & 3,00 & 2,00 & 2,00 \\
\hline
\end{tabular}

Fuente: Novaro, 2010

el informe de los resultados del procesamiento de los datos cualitativos y cuantitativos correspondientes a cada dimensión de la calidad de la democracia ${ }^{1}$. Las secciones tercera y cuarta tienen una pretensión analítica y explicativa. En la tercera se analiza la evolución de la competitividad política y de la igualdad en el período 2003-2013. La cuarta coloca a estas dos dimensiones como variables independientes para observar su impacto sobre otras dimensiones de la calidad de la democracia. La quinta y última sección sintetiza los hallazgos y conclusiones.

\section{Una evaluación de las dimensiones de la calidad de la democracia}

Esta sección presenta un resumen de los datos cualitativos y las calificaciones asignadas a cada dimensión por el "Informe sobre la calidad de la democracia en Argentina" (Novaro, 2010) construido en base al modelo analítico desarrollado por Morlino (2011). La medición de la calidad de la democracia utiliza una escala donde 0 (cero) corresponde a la calidad mínima y 5 (cinco) a la máxima. La Tabla 1 resume los resultados finales luego del procesamiento de las subdimensiones de cada dimensión, cuyas características se presentan luego en forma separada.

La seguridad individual y el orden civil pueden calificarse como relativamente altos. Las tasas de delitos y homicidios se encuentran entre las más bajas de América Latina. En el año 2008, la tasa de homicidios dolosos registrados para cada cien mil habitantes fue de 5,8, la cuarta más baja del continente americano ${ }^{2}$. En cuanto al orden civil, no existen grupos militantes extremistas, ni violencia política preocupante, ni conflictos violentos con otros Estados, aunque hay antecedentes de importantes ataques terroristas durante principios de los 1990, presuntamente con la participación de fuerzas de seguridad locales. Respecto del lugar del Poder Judicial, si bien existe un consenso sobre la independencia de la Corte Suprema, durante los últimos diez años los gobiernos de Néstor y Cristina Kirchner han conseguido

1 El "Informe sobre la calidad de la democracia en Argentina" realizado por un equipo coordinado por Novaro (2010) contiene datos para las ocho dimensiones propuestas por Morlino (2009).

2 Estadísticas en materia de criminalidad, Dirección Nacional de Política Criminal, Ministerio de Justicia, disponibles en <http://www.jus.gob.ar/ areas-tematicas/estadisticas-de-politica-criminal/tasas-de-delitos.aspx>. El dato más reciente se refiere a 2009, pero no incluye la Provincia de Buenos Aires. 
Tabla 3: Accountability electoral

\begin{tabular}{|c|c|c|c|c|}
\hline Elecciones & $\begin{array}{c}\text { Información } \\
\text { plural e } \\
\text { independiente }\end{array}$ & $\begin{array}{c}\text { Libertad de organización } \\
\text { partidaria }\end{array}$ & $\begin{array}{c}\text { Presencia y estabilidad de } \\
\text { alternativas políticas }\end{array}$ & Promedio \\
\hline 4,00 & 3,00 & 4,00 & 2,00 & 3,25 \\
\hline
\end{tabular}

Fuente: Novaro, 2010

Tabla 4: Accountability interinstitucional

\begin{tabular}{|c|c|c|c|c|c|}
\hline Relaciones Ejec.-Leg. & $\begin{array}{c}\text { Corte } \\
\text { Suprema }\end{array}$ & Ombudsman & $\begin{array}{c}\text { Tribunales } \\
\text { auditores }\end{array}$ & Descentralización & Promedio \\
\hline 3,00 & 3,00 & 3,00 & 4,00 & 4,00 & 3,40 \\
\hline
\end{tabular}

Fuente: Novaro, 2010

controlar el órgano que designa y controla a los jueces (Consejo de la Magistratura).

En relación con las capacidades administrativas, el Poder Ejecutivo cuenta con recursos humanos y materiales necesarios para desarrollar sus tareas. Sin embargo, una encuesta de Latinobarómetro muestra que el desempeño de la administración pública es calificado negativamente: en 2008 el 31,3\% consideraba el funcionamiento de las instituciones públicas como malo o muy malo, y el 52,4\%, como regular. Finalmente la legislación que regula el acceso y desempeño con respecto al empleo público no suele ser aplicada para la incorporación de agentes estatales (Scherlis, 2013).

Los niveles de corrupción se mantienen elevados, y las reiteradas denuncias, en general motorizadas por la prensa, obtienen en el Poder Judicial resultados muy limitados. En una escala de cero (percepción de muy corrupto) a diez (percepción de ausencia de corrupción), el índice de percepción de la corrupción publicado por Transparencia Internacional en 2014 ubica a Argentina en el puesto 107 entre 175 países evaluados, y en el puesto 22 entre 31 países del continente americano.

La efectividad de la legislación que establece que las fuerzas de seguridad operan bajo control civil es muy despareja según la fuerza y el territorio. La participación de miembros de fuerzas de seguridad en bandas de crimen organizado aumenta la desconfianza de la opinión pública sobre ellas.

Como se observa en la Tabla 3, existen altos niveles de participación electoral, que oscilan en torno al 80\% del electorado, en un marco de sufragio formalmente obligatorio pero sin sanciones efectivas. Las elecciones se llevan a cabo regularmente con reglas que, aunque en algunos aspectos cambiantes, suelen ser claras, y sus resultados no generan controversias o denuncias de fraude significativas. Las autoridades electorales se desempe- ñan en forma imparcial y tampoco han recibido impugnaciones. Los padrones electorales son considerados correctos, y se han instrumentado reformas administrativas para mejorar los mecanismos de su actualización.

El financiamiento de las campañas electorales, tanto público como privado, está detalladamente legislado, pero no existe transparencia en su seguimiento y cumplimiento.

Existe una gran diversidad de medios de comunicación con posturas disímiles. Sin embargo, hay algunos medios que se han convertido en grandes corporaciones mediáticas con posición dominante en el tratamiento de la información. Para enfrentar las líneas editoriales de la prensa independiente, a partir de 2009 la Presidencia de Cristina Kirchner ha alentado la creación de medios dirigidos por empresarios afines a las posiciones políticas de su gobierno financiados por publicidad oficial que funcionaron como verdaderos centros de propaganda del discurso oficial.

Existe para todos los ciudadanos el derecho de asociación política y de agrupación en partidos políticos. Se encuentran garantizadas la competitividad y la representación.

El Poder Legislativo tiene capacidades reales para intervenir en el proceso de elaboración y sanción de leyes. En los últimos años, la mayoría oficialista en el Congreso ha generado la impresión de que el Legislativo es una mera "escribanía" que refrenda las decisiones de la Presidencia, pero los estudios empíricos muestran que aun en estas circunstancias los legisladores hacen valer una multiplicidad de intereses que representan, $\mathrm{y}$ que las normas resultan de la negociación entre diversos actores (Calvo, 2014).

Los miembros de la Corte Suprema son propuestos por el Poder Ejecutivo y refrendados por el Senado. No pueden ser removidos, salvo por juicio político, lo que permite cierta estabilidad e independencia. La 
Tabla 5: Participación

\begin{tabular}{|c|c|c|c|c|c|}
\hline $\begin{array}{c}\text { Oportunidades } \\
\text { de participación }\end{array}$ & $\begin{array}{c}\text { Elecciones y } \\
\text { referéndums }\end{array}$ & $\begin{array}{c}\text { Partidos } \\
\text { y asociaciones }\end{array}$ & $\begin{array}{c}\text { Participación } \\
\text { no convencional }\end{array}$ & $\begin{array}{c}\text { Democracia } \\
\text { deliberativa }\end{array}$ & Promedio \\
\hline 4,00 & 5,00 & 3,00 & 4,00 & 2,00 & 3,60 \\
\hline
\end{tabular}

Fuente: Novaro, 2010

Tabla 6: Competitividad política

\begin{tabular}{|c|c|c|c|}
\hline $\begin{array}{c}\text { Entre actores políticos/ } \\
\text { sociales }\end{array}$ & $\begin{array}{c}\text { Al interior de actores } \\
\text { políticos/sociales }\end{array}$ & Alternancia & Promedio \\
\hline 2,50 & 3,00 & 2,50 & 2,70 \\
\hline
\end{tabular}

Fuente: Novaro, 2010

Auditoría General de la Nación (AGN) asiste al Poder Legislativo sobre el desempeño de la administración pública. Su presidente es propuesto por el principal bloque parlamentario de la oposición. Por otro lado, no tiene poder de sanción sobre las autoridades ejecutivas. Si bien la Constitución Nacional reconoce la autonomía política provincial y municipal y establece transferencias automáticas regladas por una ley de coparticipación, la Presidencia cuenta con recursos fiscales discrecionales. Son muchas las provincias que dependen de las transferencias de recursos desde el Estado nacional, lo que constituye una asimetría de poder a favor de la Presidencia.

Hay amplias oportunidades de participación: existen derecho universal al voto, elección directa del jefe de Estado y posibilidad de consulta popular (referéndum) e iniciativa ciudadana, aunque su utilización fue muy limitada debido a que las reglamentaciones dificultan su aplicación.

Los datos electorales reflejan que la ciudadanía asiste mayoritariamente a las elecciones, tanto ejecutivas como legislativas. Por otra parte, la población tiene un amplio acceso a distintos canales de información. La participación en los partidos políticos puede calificarse como media: el número de afiliados es comparativamente alto, pero hay consenso respecto a que los registros, que crecieron fuertemente con el regreso a la democracia en 1983, deberían ser actualizados. El número de adherentes a los partidos está en constante declive.

Entre las formas de participación no convencionales se destaca el predominio de las protestas sindicales. En los últimos 15 años es relevante señalar la existencia de diferentes movimientos colectivos, con intereses específicos, que han tenido intermitente presencia en el espacio público, como por ejemplo piqueteros, ruralistas, ahorristas, inmigrantes, desempleados, homosexuales, ecologistas, jubilados, entre otros. Desde la crisis de 2001 cabe destacar al movimiento territorial de desocupados, denominado piqueteros, cuyo accionar implicaba cortes de calles y rutas. Puede concluirse que en términos generales la participación política más allá del proceso electoral transcurre por canales alternativos a los partidos políticos.

El grado de competitividad política del sistema de partidos se ha ido reduciendo a lo largo de los 32 años de democracia desde 1983. El Partido Justicialista (PJ) es actualmente predominante en el sistema político, con una oposición muy fragmentada y sin fuertes liderazgos. Hay una enorme diferencia de poder territorial y electoral. El PJ ha ocupado la Presidencia de la Argentina por 24 de los últimos 26 años. La centralidad del peronismo reconduce la competencia por la Presidencia del país al interior del PJ. De modo que cómo el peronismo resuelve sus conflictos internos por el liderazgo ha devenido en un asunto que adquiere tanta o incluso mayor relevancia que la relación entre el peronismo gobernante y los partidos opositores no peronistas.

Existe una alta percepción de legitimidad del sistema democrático. Según Latinobarómetro, en 2013 el $72,8 \%$ de los argentinos consideraba a la democracia como preferible ante cualquier otra forma de gobierno. Pero hay una baja credibilidad hacia las principales instituciones. Para el 48,1\% de los ciudadanos (según datos del 2012) el gobierno nacional no se ocupa de sus preocupaciones, y para el 33,7\% sólo lo hace a medias ${ }^{3}$. La satisfacción de los ciudadanos con los resultados que producen los políticos en funciones de gobierno se mantiene baja: una encuesta de Latinobarómetro de 
Tabla 7: Responsividad

\begin{tabular}{|c|c|c|}
\hline Legitimidad percibida & Constreñimientos a la democracia & Promedio \\
\hline 3,00 & 2,00 & 2,50 \\
\hline
\end{tabular}

Fuente: Novaro, 2010

Tabla 8: Libertad

\begin{tabular}{|c|c|c|c|}
\hline Dignidad personal & Derechos civiles & Derechos políticos & Promedio \\
\hline 4,00 & 3,50 & 4,00 & 3,80 \\
\hline
\end{tabular}

Fuente: Novaro, 2010

Tabla 9: Igualdad

\begin{tabular}{|c|c|c|c|}
\hline $\begin{array}{c}\text { Distribución de recursos } \\
\text { económicos, culturales y sociales }\end{array}$ & $\begin{array}{c}\text { Existencia de } \\
\text { discriminación }\end{array}$ & $\begin{array}{c}\text { Derechos sociales, } \\
\text { económicos y culturales }\end{array}$ & Promedio \\
\hline 3,50 & 3,00 & 3,00 & 3,20 \\
\hline
\end{tabular}

Fuente: Novaro, 2010

2005 muestra que el 85,7\% consideraba que los políticos se preocupaban poco o nada por los intereses de la ciudadanía.

La Constitución proclama el derecho a la vida y prohíbe la pena de muerte. Se garantiza que nadie será sometido a torturas ni a tratos o penas crueles, inhumanos o degradantes. En la práctica, sin embargo, existen denuncias contra agentes de las fuerzas de seguridad que sólo excepcionalmente son elevadas a juicio. En materia de DDHH, el Estado argentino condenó y persiguió los crímenes de lesa humanidad perpetrados por regímenes autoritarios. Existen previsiones constitucionales y legales, además de la adhesión a los tratados internacionales, que amparan los derechos, libertades y garantías de las personas (y de las minorías) en sus más diversas formas. Se reconocen las libertades de expresión, de asociación, de pensamiento y religiosa.

En Argentina existen grandes desigualdades sociales y regionales. Sin embargo, si contabilizamos el período que va de 2001 a 2012 el índice de Gini que mide la desigualdad en la distribución de los ingresos se redujo de 0,534 en 2001 a 0,445 en $2012^{4}$. Según el Instituto Nacional de Estadísticas y Censos (INDEC), la tasa de indigencia se redujo del 27,7\% de la población en 2003 al 8,7\% en 2006. Para el mismo período, la pobreza se redujo del 54\% al 26,9\%. A partir de 2007 no existen datos oficiales confiables, lo que debilita el análisis del período completo 2003-2013. Sin embargo, puede señalarse la promoción de políticas activas, amparadas por la legislación, para incluir a los sectores más vulnerables de la población, como las pensiones no contributivas (cuyos beneficiarios crecieron un 260\% entre 2001 y 2011) y la asignación universal por hijo que alcanzó los 3.424.458 beneficiarios a mediados de 2012 .

\section{Las variables independientes: los cambios en la competitividad política y la igualdad (2003-2013)}

En esta sección nos centramos en dos dimensiones cuya varianza e impacto en las otras justifican su utilización analítica como variables independientes para explicar la evolución de la calidad de la democracia en Argentina durante el período en estudio (2003-2013). En primer lugar, hemos seleccionado la competitividad política, una dimensión cuya varianza significativa influye decisivamente en las condiciones de la calidad de la democracia, principalmente en Estado de derecho, rendición de cuentas, la responsividad y las libertades (Morlino, 2007).

Como segunda variable independiente, se ha seleccionado a la dimensión igualdad, que también cumple el requisito de una varianza significativa a partir de 2003. Considerada como una dimensión sustantiva de la calidad democrática (Morlino, 2009), la igualdad suele ser observada más como un efecto del desempeño 
de otras dimensiones (variable dependiente) que como una variable que afecta el Estado de derecho, la rendición de cuentas, etc. Por ello la relevancia de la igualdad como variable independiente que impacta sobre las demás dimensiones es usualmente mucho menor que en el caso de la competitividad política. En principio, cabe esperar que un aumento en la igualdad conlleve un impacto positivo sobre la calidad de la democracia. La expectativa habitual es precisamente que la reducción de las desigualdades y la conquista de derechos sociales impacten positivamente en la relación de los ciudadanos con sus representantes políticos, aumentando los índices de participación política, de rendición de cuentas y de responsividad. Sin embargo, determinadas formas de reducir desigualdades podrían también tener efectos negativos. Aunque esto no ha merecido en general mayores análisis, la idea sugiere que allí donde las instituciones estatales no están consolidadas, la "abundancia" puede entrar en tensión con la eficiencia y la transparencia. Una coyuntura de abundancia de recursos fiscales en manos de un presidente carente de control institucional y ciudadano puede inducir al Poder Ejecutivo a aprovechar los márgenes de manipulación del gasto, reproduciendo la opacidad y la ineficiencia en la asignación de recursos. Si esto se combina con ciudadanos que asisten a un proceso de mejora de la igualdad, que los vuelve más propensos a valorar positivamente a los protagonistas políticos que lideran ese proceso que a exigirles transparencia y eficiencia, la coyuntura de igualación podría también interpretarse como una limitación al mejoramiento de los mecanismos procedimentales de calidad de la democracia que a un resultado producto de una mayor calidad.

América Latina cuenta con una profusa experiencia de gobiernos que propician políticas económicas de distribución del ingreso en momentos de expansión económica mientras que, simultáneamente, recelan de los componentes más asociados a las tradiciones liberales y republicanas de la democracia. Guillermo O'Donnell dedicó parte de sus esfuerzos intelectuales desde comienzos de los años 1990 a comprender este tipo de situaciones, a las que caracterizó por la ausencia de "accountability horizontal". Otros autores prefieren hablar de una tradición populista, en la cual cierta preocupación por la igualdad es acompañada por el desdén hacia el pluralismo, los controles al poder y el respeto por el Estado de derecho (por ejemplo Zanatta, 2008). En el marco de este esquema conceptual, la reducción de las desigualdades no empodera a los ciudadanos ni necesariamente da lugar a una sociedad civil más vibrante. Por el contrario, puede fomentar la exaltación de la figura del líder, a quien se identifica como el realizador exclusivo de esa reducción de desigualdades.

En una perspectiva más matizada, las políticas que aumentan el nivel de consumo básico pueden incentivar comportamientos conformistas, relajando el compromiso por el control a la acción gubernamental y generando mayor tolerancia en las acciones del gobierno que claramente debilitan diferentes dimensiones de la calidad democrática, como los controles interinstitucionales, la libertad de prensa, etc. De modo que la satisfacción por las mejoras en el campo de la igualdad puede, directa o indirectamente, reducir la exigencia de mayores controles, transparencia y eficiencia en los mecanismos de distribución de recursos, afectando, en última instancia, variables procedimentales clave como el Estado de derecho, la rendición de cuentas y la responsividad.

A continuación, se describe la evolución de las variables independientes competitividad política e igualdad en el período 2003-2013 en Argentina.

\section{a) Competitividad política}

La competitividad del sistema de partidos en Argentina ha experimentado cambios desde el retorno de la democracia en 1983. Durante ese lapso el Partido Justicialista fue adquiriendo progresivamente un lugar dominante en el sistema de partidos.

En una primera etapa, que va desde la recuperación democrática en 1983 hasta 1991, la competitividad política adoptó una dinámica bipartidista cuyos actores protagónicos eran los tradicionales partidos argentinos del siglo XX: la Unión Cívica Radical (UCR) y el PJ. Como se observa en la Figura 1, la UCR ganó la Presidencia en 1983 (Raúl Alfonsín) con más del 50\% de los votos, y la oposición quedó claramente representada por el PJ $(40 \%)$. La dinámica bipartidista se mantuvo hasta las parlamentarias de 1991, ya con el peronista Carlos Menem (1989-1999) en la Presidencia.

Entre los años 1992 y 2001 se puede identificar una segunda etapa caracterizada por un sistema multipartidista que incentivó la formación de coaliciones. El fortalecimiento del PJ gobernante y el debilitamiento de la UCR dejaron un espacio para la emergencia de nuevos partidos -como el Frepaso- con capacidad de representación nacional. La alianza UCR-Frepaso derrotó al PJ en la elección presidencial de 1999, constituyendo un gobierno que presidió Fernando de la Rúa (1999-2001). Esta segunda etapa termina con una feroz crisis económica y social que fuerza la renuncia de De la Rúa hacia finales de 2001.

Como resultado de la crisis, se relajaron las identificaciones partidarias, sobre todo las no peronistas, y el voto de este electorado se volvió más volátil. La tercera etapa se abrió a comienzos de 2002 y se caracteriza por un marcado predominio del peronismo sobre el sistema político argentino. Ello supone, por un lado, la ubicación del PJ como partido dominante con líderes nacionales y territoriales fuertes. Y por otro, una oposición muy fragmentada con un anclaje institucional y territorial volátil y débil, y liderazgos con capacidad de representación territorialmente acotada. 
Figura 1: Elecciones presidenciales (1983-2011)

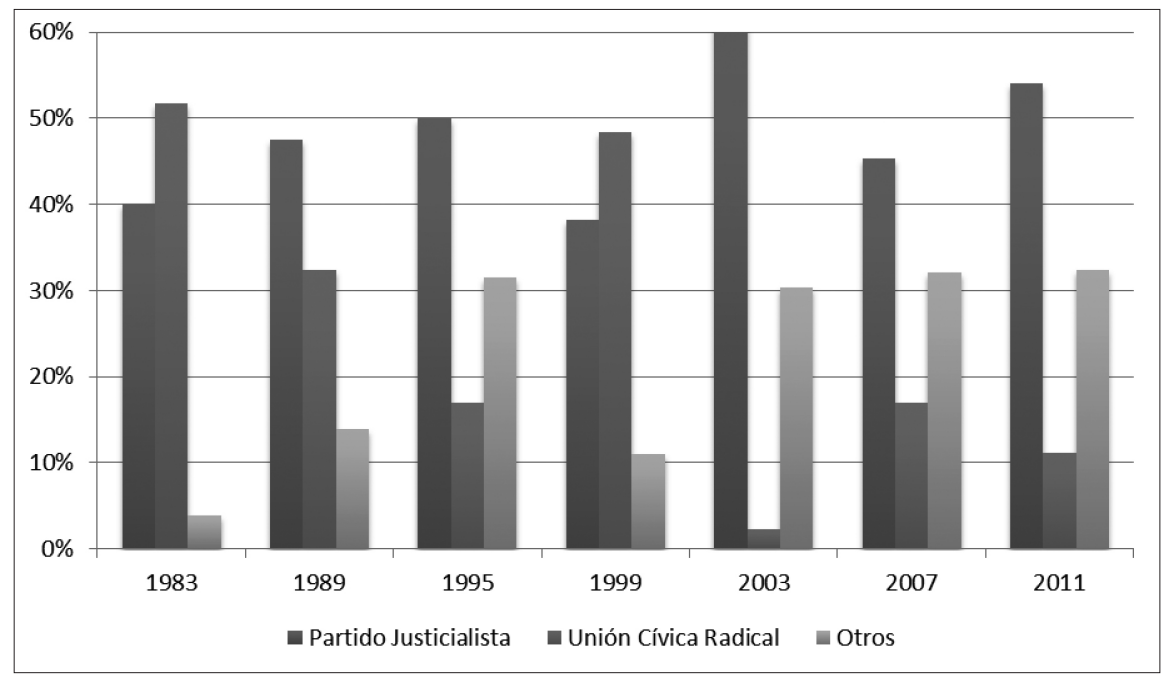

Nota: En la elección 2003 el Partido Justicialista habilito a competir a tres candidatos distintos. El resultado es la suma de los tres. Fuente: Elaboración propia sobre datos de la Dirección Nacional Electoral de Argentina

Figura 2: Distribución de gobernaciones por período

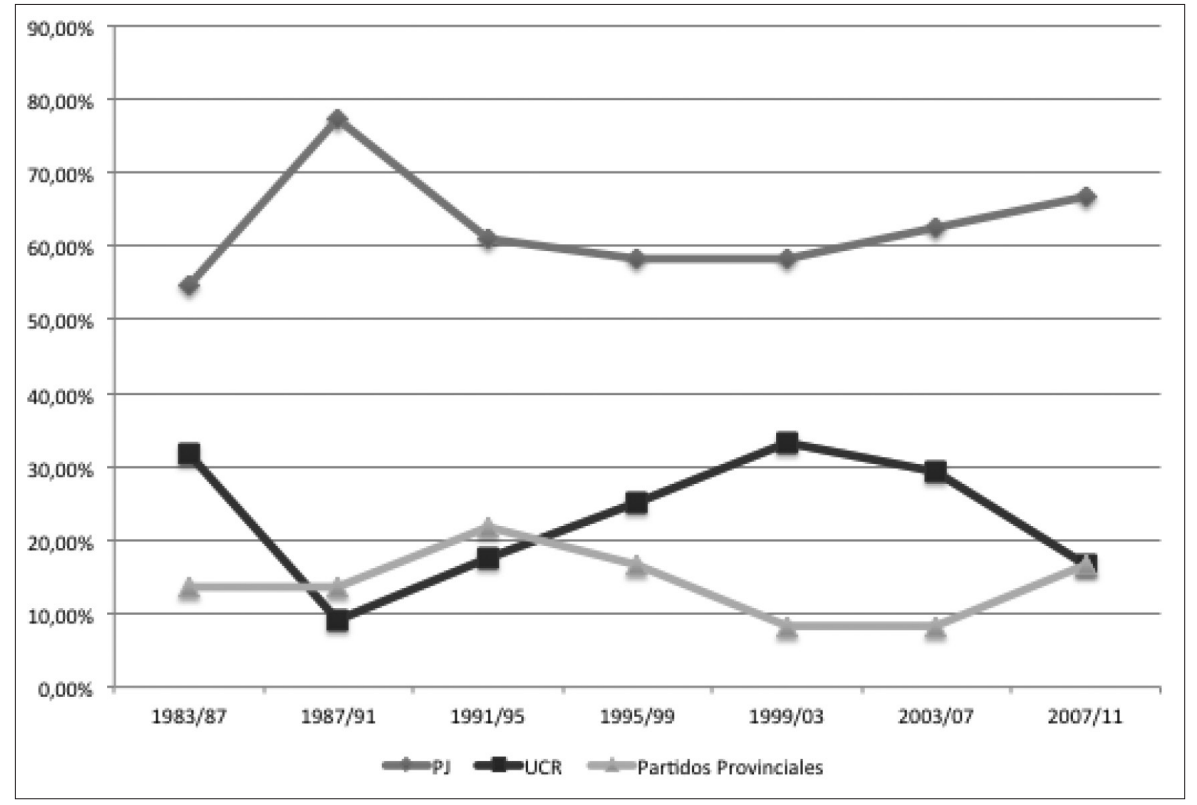

Fuente: Elaboración propia

Las elecciones de 2003 expresaron el dominio del PJ y la debilidad de las fuerzas políticas alternativas: tres candidatos surgidos del PJ se disputaron la Presidencia y concentraron más del $60 \%$ de los votos. Lo que revela una tercera faceta de la década de 2000: la dominancia del PJ ha reenviado la competitividad política por la alternancia al interior del peronismo, que funciona, en palabras de Juan Carlos Torre (1999), como un "sistema político" en sí mismo. Las elecciones en las que triunfó Cristina Fernández de Kirchner en 2007 y 2011 mostraron baja competitividad y pocas alternativas electorales reales al kirchnerismo, algunas de las cuales se desprendieron del propio PJ.
En suma, las elecciones en Argentina desde el retorno de la democracia hasta 2001 mostraron una alternancia posible y efectiva. Los triunfos de la UCR en las presidenciales de 1983 y 1999 (en este último caso en coalición con el Frepaso) mostraban un partido con una estructura partidaria federal que lo volvía competitivo y que era capaz de generar líderes partidarios con capacidad de representación ciudadana. Sin embargo, el modo en que terminaron ambas experiencias de gobierno -con crisis económicas y entregando a Presidencia con anticipación- afectaron significativamente su relación con la opinión pública. A lo largo de la década del 2000 el comportamiento de la oposición ha contribuido a 
Tabla 10: Resultados de las elecciones presidenciales (1983-2011)

\begin{tabular}{|l|c|c|c|c|c|c|c|}
\hline & $\mathbf{1 9 8 3}$ & $\mathbf{1 9 8 9}$ & $\mathbf{1 9 9 5}$ & $\mathbf{1 9 9 9}$ & $\mathbf{2 0 0 3}$ & $\mathbf{2 0 0 7}$ & $\mathbf{2 0 1 1}$ \\
\hline PJ & $40 \%$ & $47 \%$ & $50 \%$ & $38 \%$ & $61 \% * *$ & $45 \%$ & $54 \%$ \\
\hline UCR & $52 \%$ & $32 \%$ & $17 \%$ & $48 \% *$ & $2 \%$ & $17 \% * * *$ & $11 \%$ \\
\hline ARI / CC & - & - & - & - & $14 \%$ & $23 \%$ & $1 \%$ \\
\hline Recrear & - & - & - & - & $16 \%$ & $1 \%$ & - \\
\hline Frepaso & - & - & $29 \%$ & - & - & - & - \\
\hline
\end{tabular}

Fuente: Elaboración propia

* La UCR compite en coalición con el Frepaso.

** El PJ compite con tres opciones electorales.

*** La UCR va en coalición con parte del peronismo.

Tabla 11: Competitividad partidaria a nivel nacional

\begin{tabular}{|c|c|c|c|}
\hline Etapas & 1983-1991 & $\mathbf{1 9 9 2 - 2 0 0 1}$ & $\mathbf{2 0 0 2 - 2 0 1 1}$ \\
\hline & & PJ: $55 \%$ & PJ: $65 \%$ \\
$\begin{array}{c}\text { Distribución del poder } \\
\text { electoral }\end{array}$ & UCR: $50 \%$ & UCR: $25 \%$ & UCR: $15 \%$ \\
& PJ: $50 \%$ & Frepaso: $20 \%$ & $20 \%$ \\
\hline
\end{tabular}

Fuente: Elaboración propia

Tabla 12: Competitividad e igualdad (1983-2012)

\begin{tabular}{|c|c|c|}
\hline & Competitividad & Igualdad \\
\hline 1983-1990 & $\begin{array}{l}\text { Bipartidismo } \\
\text { PJ-UCR }\end{array}$ & $\begin{array}{l}\text {-Estancamiento económico } \\
\text {-Baja provisión de bienes públicos y privados } \\
\text {-Instituciones laborales fuertes } \\
\text {-Bajo desempleo }\end{array}$ \\
\hline 1991-1996 & $\begin{array}{l}\text { Multipartidismo moderado } \\
\text { PJ-UCR-Frepaso }\end{array}$ & $\begin{array}{l}\text {-Crecimiento económico moderado } \\
\text {-Media provisión de bienes públicos y privados } \\
\text {-Instituciones laborales débiles } \\
\text {-Alto desempleo }\end{array}$ \\
\hline 1997-2002 & $\begin{array}{l}\text { Multipartidismo moderado } \\
\text { PJ-UCR-Frepaso }\end{array}$ & $\begin{array}{l}\text {-Estancamiento económico } \\
\text {-Baja provisión de bienes públicos y privados } \\
\text {-Instituciones laborales débiles } \\
\text {-Alto desempleo }\end{array}$ \\
\hline 2003-2012 & $\begin{array}{l}\text { Partido dominante } \\
\text { PJ }\end{array}$ & $\begin{array}{l}\text {-Alto crecimiento económico } \\
\text {-Alta provisión de bienes públicos y privados } \\
\text {-Instituciones laborales fuertes } \\
\text {-Bajo desempleo }\end{array}$ \\
\hline
\end{tabular}

Fuente: Elaboración propia

la predominancia del peronismo. En primer lugar, su incapacidad para construir coaliciones electorales alternativas en momentos de división o debilidad del gobierno peronista (por ejemplo las elecciones legislativas de 2009). La oposición se presentó siempre con una oferta electoral fragmentada que volvió prácticamente imposible que alguno de los candidatos pudiese emerger como challenger y así polarizar la elección. Por otra parte, potenciales líderes opositores fueron incapaces de concitar una adhesión ciudadana suficiente como para aglutinar detrás a los fragmentos opositores: en 2011, mientras la presidenta logró su reelección con 54,1\%, quien la siguió en cantidad de votos, el socialista Hermes Binner, obtuvo 16,8\%.

Por su parte, la estructura flexible del PJ (Levitsky, 2005), su dominio territorial y el éxito en las fórmulas 
de gobernabilidad que enhebraron los gobiernos peronistas de Menem, Duhalde, Kirchner y Fernández de Kirchner lograron imponer en amplios sectores de la sociedad la idea de que sólo un presidente peronista puede gobernar la Argentina. O su reverso: que es extremadamente dificil para un presidente gobernar con éxito con el peronismo en la oposición.

\section{b) Igualdad}

Todos los índices y los trabajos empíricos que miden los índices de desigualdad de Argentina en la década del 2000 muestran una muy sensible mejora (por ejemplo Cruces y Gasparini, 2009) con respecto a los últimos años de la década de 1990. Como puede observarse en las siguientes figuras, el coeficiente Gini, que mide las desigualdades, y los niveles de pobreza e indigencia han descendido drásticamente.

Dicho comportamiento puede explicarse por una serie de elementos:

1. El desempeño macroeconómico argentino desde el regreso de la democracia se caracterizó por un bajo crecimiento y alta volatilidad. Sin embargo, desde 2002 se inició un proceso de recuperación y crecimiento económico sostenido a altas tasas cuyo impacto fue un pronunciado descenso del desempleo y el acceso a bienes de consumo a grandes sectores de la población.

Figura 3: Evolución del coeficiente Gini (1991-2010)

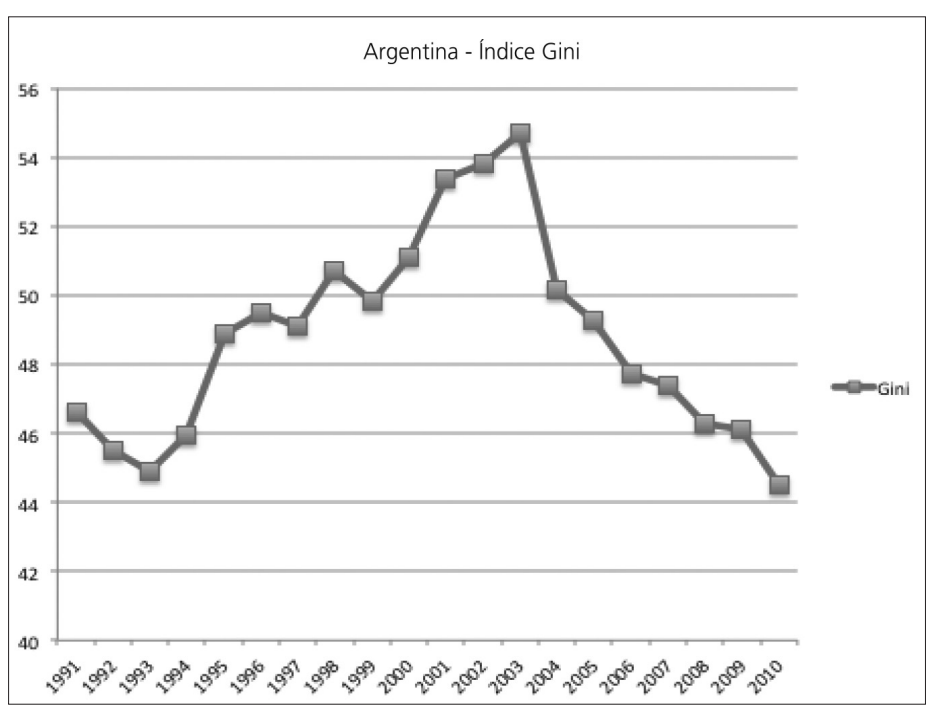

Fuente: Elaboración propia sobre datos del Banco Mundial

Figura 4: Evolución de la pobreza y la indigencia (1992-2010)

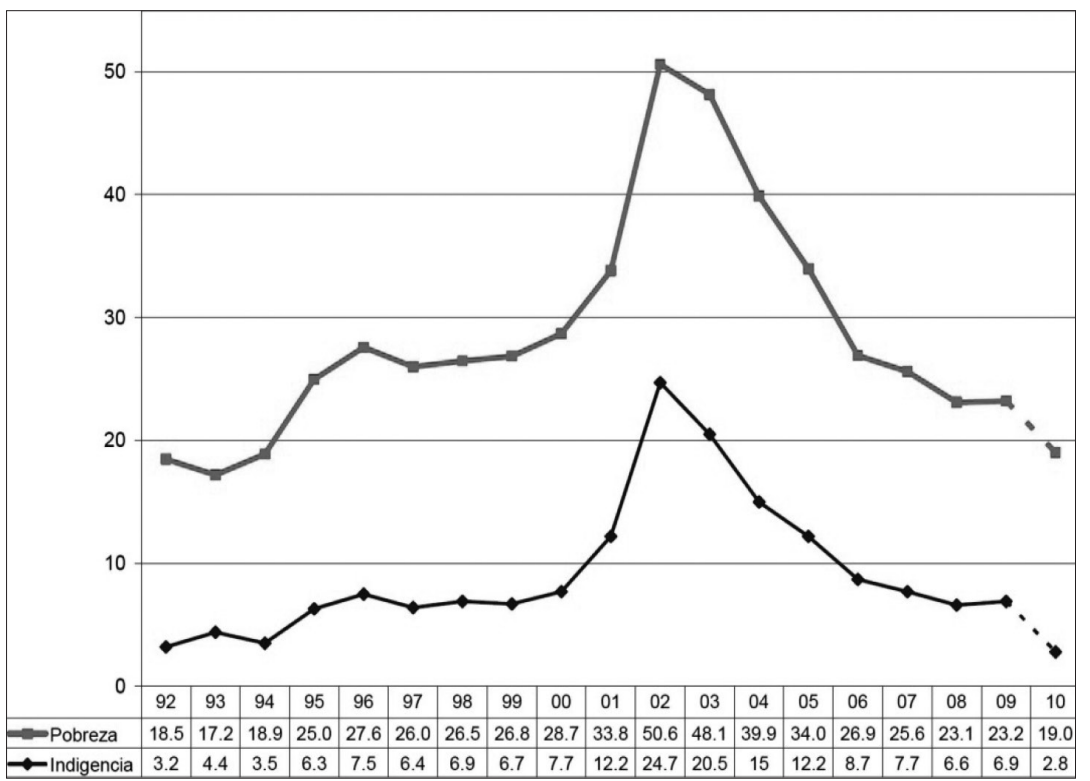

Fuente: Cruces y Gasparini (2010) 


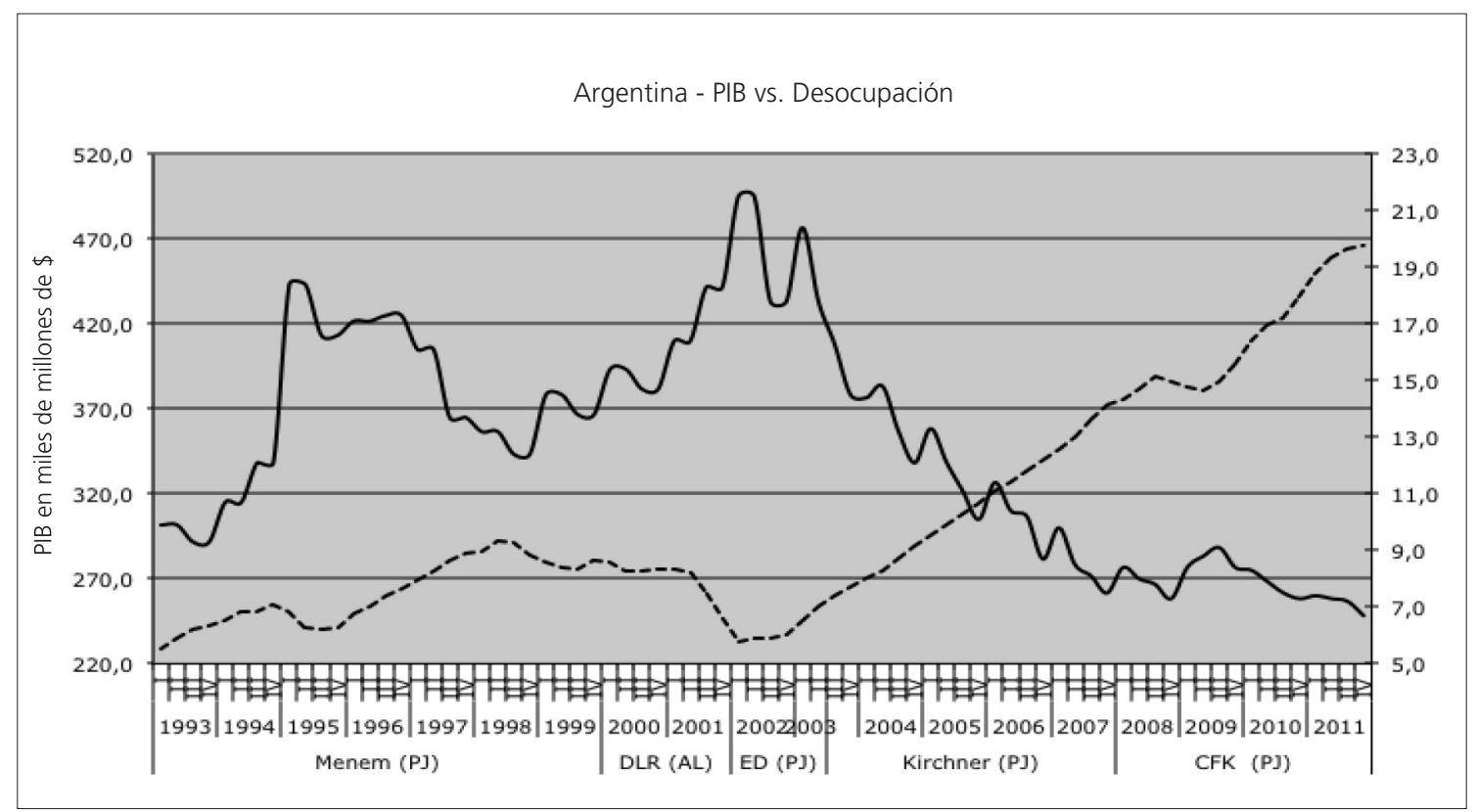

Fuente: Elaboración propia sobre datos del INDEC

Tabla 13: Impacto de la AUH sobre la pobreza

\begin{tabular}{|c|c|c|c|c|}
\hline & \multicolumn{4}{|c|}{ Asignación universal por hijo } \\
\hline & Actual & A & B & C \\
\hline \multicolumn{5}{|c|}{ Tasa de pobreza (en porcentaje) } \\
\hline \multicolumn{5}{|l|}{ Tasa de pobreza total } \\
\hline Pobreza extrema & 6.9 & 3.2 & 3.6 & 2.8 \\
\hline Pobreza moderada & 23.2 & 21.1 & 20.6 & 19.0 \\
\hline \multicolumn{5}{|c|}{ Tasa de pobreza en niños } \\
\hline Pobreza extrema & 12.0 & 4.4 & 5.2 & 3.7 \\
\hline Pobreza moderada & 36.0 & 32.0 & 31.3 & 28.3 \\
\hline \multicolumn{5}{|l|}{ Brecha de pobreza } \\
\hline Pobreza extrema & 2.9 & 1.1 & 1.3 & 0.9 \\
\hline Pobreza moderada & 9.3 & 6.6 & 6.7 & 5.7 \\
\hline \multicolumn{5}{|c|}{ Tasa de pobreza en niños } \\
\hline Pobreza extrema & 4.9 & 1.2 & 1.6 & 0.8 \\
\hline Pobreza moderada & 15.2 & 9.6 & 10.1 & 8.2 \\
\hline \multicolumn{5}{|c|}{ Desigualdad de ingresos } \\
\hline Ratio 10/1 & 23.7 & 17.2 & 18.0 & 16.5 \\
\hline Share decill 1 & 1.4 & 1.9 & 1.8 & 2.0 \\
\hline Gini & 0.455 & 0.442 & 0.441 & 0.435 \\
\hline Atkinson (2) & 0.569 & 0.485 & 0.495 & 0.473 \\
\hline
\end{tabular}

Fuente: Cruces y Gasparini, 2010

Nota: Las alternativas cubren a) informales con salario menor al mínimo que mandan a sus hijos a escuelas públicas; b) informales que mandan a sus hijos a escuelas públicas; c) todos los informales.

2. Una mejora de la cobertura social de los menos favorecidos. El Plan Jefas y Jefes de Hogar creado en 2002 y la Asignación Universal por Hijo (AUH) de 2009 tuvieron un fuerte impacto en la inclusión social y la reducción de la indigencia y la pobreza extrema (Galasso y Ravallion, 2003; Cruces y Gasparini, 2010). En la Tabla 13, tomada de Cruces y Gasparini (2010), se observa el impacto estimado de la AUH en tres escenarios, y en todos ellos el impacto es muy significativo.

3. El gobierno de Néstor Kirchner, por medio de la reactivación de una institución que revisa el salario mínimo, ha impulsado el aumento del salario mínimo vital y móvil (S.M.V.M.), que pasó de $\$ 300$
(USD 100) en 2003 a $\$ 4.716$ (USD 555) a fines de 2014.

4. El gobierno de Cristina Kirchner dispuso en el año 2008 la eliminación del sistema de jubilaciones y pensiones privado (AFJP) y el retorno a un sistema de reparto público de jubilaciones. Como la evolución de la producción y del empleo formal fue de notable crecimiento en la década de 2000 , el rendimiento del sistema de pensiones aumentó. La decisión política de priorizar las condiciones de vida de los adultos mayores permitió una mejora en los recursos destinados a las prestaciones y la extensión de la cobertura (Bertranou et al., 2012). Por medio de la modalidad contributiva tradicional, 
Figura 6: Evolución del salario mínimo (1993-2012)

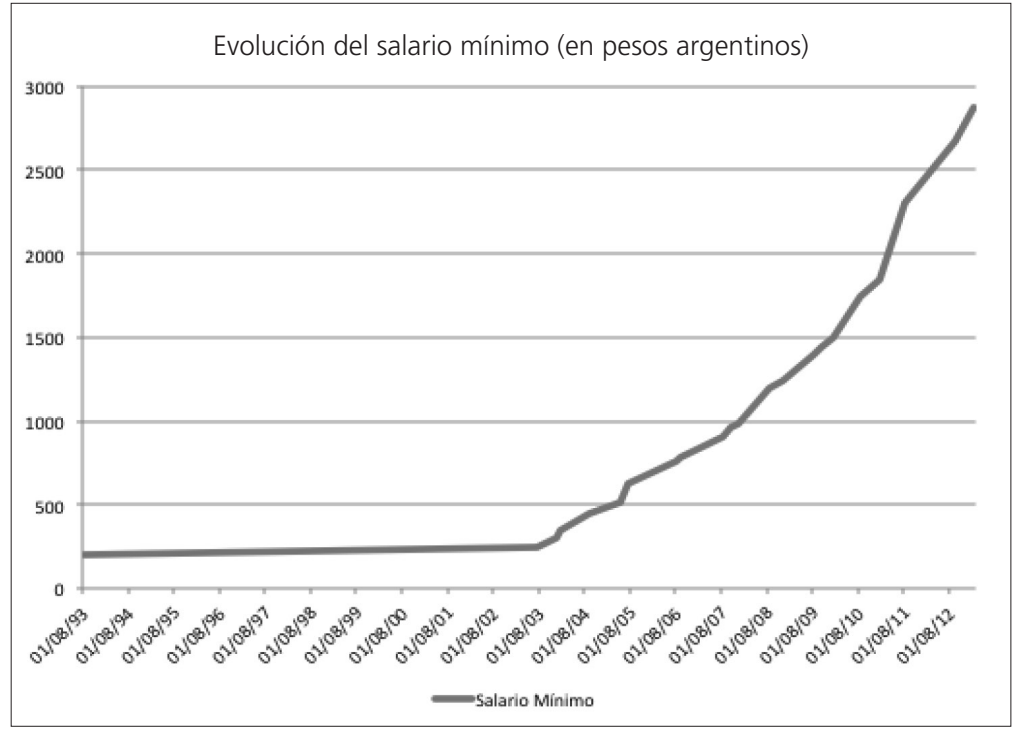

Fuente: Estudio EIC

Figura 7: Variación interanual de la inflación

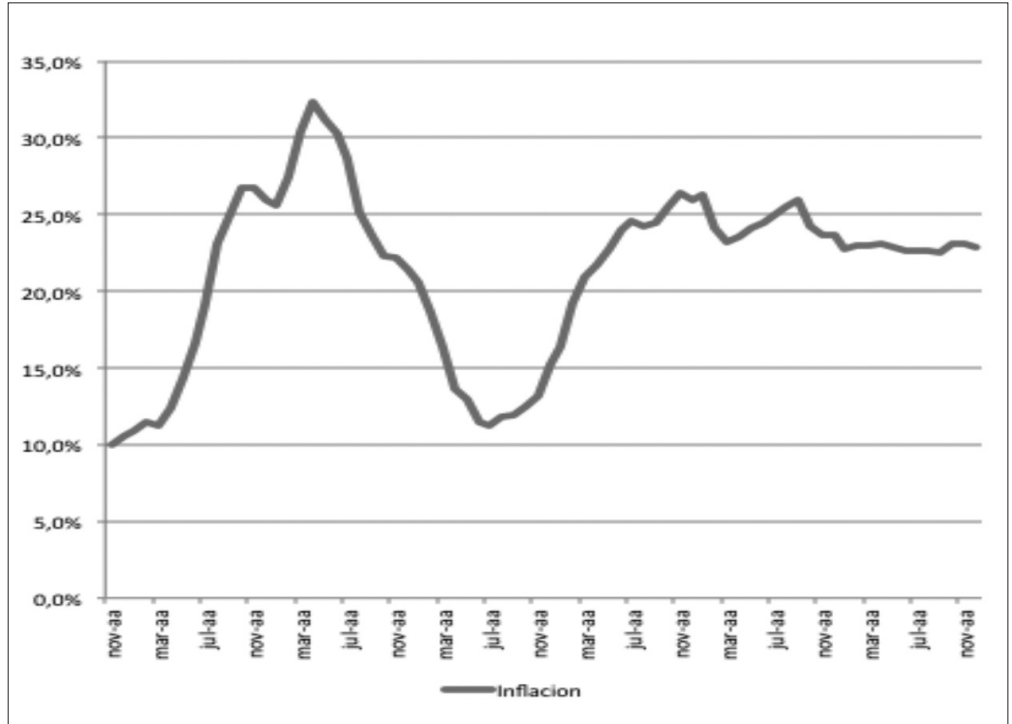

Fuente: Cosas que Pasan en base a Direcciones Provinciales de Estadística (http://elhombrecitodelsombrerogris. blogspot.com/)

el sistema incluye cerca de 3 millones de personas, a los que se agregaron en los últimos años otros 2,4 millones de beneficiarios de las jubilaciones a través del "plan de inclusión previsional" (Repetto y Dal Masetto, 2011) ${ }^{5}$. Bertranou et al. (2012) muestran que en la última década, la cobertura de pensiones aumentó de $71 \%$ en 2001 al $91 \%$ en 2010 y las contribuciones se recuperaron como una fuente de financiación fiscal que aumentó mucho como consecuencia de la mejora del empleo formal, el aumento de los salarios reales y la nacionalización del componente de capitalización individual. En suma, la mejora en los indicadores de igualdad es significativa a lo largo de la década.

Sin embargo, el incremento de la inflación a partir del año 2008 ha limitado los alcances de las políticas tendientes a reducir las desigualdades y combatir la pobreza. Dicho incremento ha coincidido con el falseamiento de las estadísticas de precios al consumidor que tradicionalmente genera el INDEC. La manipulación de los índices de inflación desde 2007 sobreestima crecientemente

5 Se trata de personas retiradas que por requisitos de las contribuciones quedaron precarizadas en el mercado laboral. El plan de inclusión les dio actualmente una asignación mediante la flexibilización de las condiciones de acceso (Repetto y Dal Masetto, 2011). 
la mejora de los indicadores de igualdad y resta credibilidad a la comunicación gubernamental sobre la efectividad de sus políticas para reducir las desigualdades. Según la estadística manipulada por el gobierno nacional, el salario real se encuentra un $80 \%$ mejor respecto al 2001 , pero solo un $17 \%$ mejor de acuerdo con datos de inflación medidos con índices que elaboran algunas provincias. ${ }^{2}$

El mantenimiento de una inflación relativamente alta ha sido la debilidad más evidente del modelo económico impulsado por los sucesivos gobiernos kirchenristas. La figura 7 presenta datos de inflación que provienen de un promedio de los índices de precios al consumidor de las distintas provincias argentinas.

\section{El impacto de la baja competitividad y la reducción de la desigualdad en las dimensiones de la calidad de la democracia}

Creemos relevante preguntarnos cómo impactan los cambios en los niveles de competitividad política y de igualdad en el comportamiento de otras dimensiones de la calidad de la democracia. Más en particular, nos preguntamos cómo afecta la disminución de los niveles de competencia y el mejoramiento de los índices de igualdad sobre el Estado de derecho y sobre la rendición de cuentas electoral e interinstitucional. La Tabla 14 resume esta relación, que se desarrolla en los siguientes párrafos.

\section{a) Estado de derecho}

Independencia de la Justicia. Devolver independencia a la Corte Suprema reemplazando jueces partidistas por figuras con prestigio e idoneidad fue una de las primeras acciones del gobierno de Néstor Kirchner (2003-2007) a los pocos meses de asumir la Presidencia. De hecho, la Corte Suprema ha mostrado altos niveles de independencia fallando a veces a favor pero otras también en contra de la posición del gobierno en casos de fuerte relevancia política, como por ejemplo en 2013 al declarar inconstitucional el proyecto del Ejecutivo para elegir por voto popular a los miembros del organismo encargado de la selección de jueces.

Por el timing de las designaciones -al comienzo del mandato- es posible argumentar que la debilidad inicial del gobierno de Kirchner pudo haber influido en el fortalecimiento de la independencia de la Justicia. Kirchner había llegado al gobierno sólo con el 23\% de los sufragios y necesitaba fortalecer su posición ante la opinión pública. Dicha medida produjo una gran adhesión ciudadana al presidente en el comienzo de su mandato. De modo que la fragmentación partidaria y la ausencia de liderazgo inicial pueden interpretarse como el momento de mayor competitividad en el gobierno presidido por Néstor Kirchner.

El proceso de renovación de la Corte Suprema de Justicia con magistrados independientes del gobierno que impulsó Kirchner en 2003 y 2004 contrasta con la reforma que tres años más tarde hizo de la composición del Consejo de la Magistratura, organismo dedicado al nombramiento y evaluación de la actuación de los jueces. Al aumentar la proporción de representantes políticos la reforma incrementó el peso del partido de gobierno en el organismo colegiado (Gargarella, 2011). Ese no fue el único mecanismo que el gobierno kirchnerista utilizó para influir sobre la Justicia: la dilación deliberada de los concursos para cubrir vacantes en los juzgados por medio de jueces "subrogantes", es decir, funcionarios sobre los que cuenta con discrecionalidad tanto para su designación como para su remoción. Si bien este procedimiento fue declarado inconstitucional por la Corte Suprema en 2007, hacia 2010 más de un $22 \%$ de los juzgados seguían encabezados por jueces subrogantes (Garrido, 2010).

Lucha contra la corrupción. Tanto el gobierno de Néstor y como el de Cristina Kirchner (2007-2015) fueron reacios a colaborar en casos de denuncias de corrupción sobre miembros del gabinete presidencial o el gobierno en general. Buscaron para ello manipular y obstaculizar las investigaciones judiciales, eligiendo y colocando en causas que lo involucraron a jueces afines al gobierno. La ausencia de alternativas de gobierno en la oposición puede interpretarse como un poderoso desincentivo a la transparencia en la gestión de los asuntos públicos por parte del gobierno nacional.

Algunas de las instituciones estatales cuyas competencias más claramente aluden a la lucha contra la corrupción fueron reducidas en sus capacidades, desactivadas, u obstaculizadas en su accionar. La Oficina Anticorrupción, creada en 1999 en el seno del Poder Ejecutivo, tuvo muy pocos resultados hasta 2004 -formulando algunas denuncias que tomaron estado público- y ninguno a partir de ese año. Kirchner creó en 2003 una subsecretaría denominada "para la reforma institucional y fortalecimiento de la democracia", designando al frente de ella a una personalidad destacada por su actuación en una ONG dedicada a la lucha 
Tabla 14: Impacto de la competitividad política y la igualdad sobre el Estado de derecho

\begin{tabular}{|l|l|l|}
\hline \multicolumn{1}{|c|}{ Positivo } & Neutral & \multicolumn{1}{c|}{ Negativo } \\
\hline Corte Suprema independiente (C) & & $\begin{array}{l}\text { Consejo de la Magistratura dominado por el Ejecutivo (C) } \\
\text { Jueces y camaristas pro-gobierno (C) }\end{array}$ \\
\hline & & Ausencia de lucha contra la corrupción (C) \\
\hline & & $\begin{array}{l}\text { Partidización del Estado (C) } \\
\text { Sin incentivos para mejorar las capacidades administrativas (I) }\end{array}$ \\
\hline
\end{tabular}

(C) Corresponde a una subdimensión influenciada por la competitividad política

(I) Corresponde a una subdimensión influenciada por la igualdad

contra la corrupción. La subsecretaría tenía entre otras funciones hacer un seguimiento del cumplimiento del derecho a la información pública y publicaba en su página web un registro de las audiencias de los funcionarios del Poder Ejecutivo. Sin embargo, esta subsecretaría fue perdiendo apoyo político, dejó de cumplir funciones vinculadas a la transparencia de la administración y se concentró sobre todo en proveer recursos a la organización política de su nuevo director (La Cámpora), quien ejecutó un drástico reemplazo del personal. El control por parte de la Presidencia de la mayor parte de los juzgados federales (encargados de tramitar causas contra la corrupción) ha implicado el mayor freno al avance de las investigaciones. El caso más resonante ha sido la denuncia por enriquecimiento ilícito de Néstor y Cristina Kirchner, cuyo patrimonio se incrementó exponencialmente -según sus propias declaraciones juradas de bienes- desde su acceso a la función pública.

Finalmente, la Sindicatura General de la Nación, organismo encargado de controlar el funcionamiento y los gastos del Poder Ejecutivo, fue desactivada por medio de la designación de autoridades comprometidas con el partido gobernante (la número dos del organismo fue desde 2003 y hasta 2008 la esposa del ministro de planificación, a quien debía obviamente controlar). Como resultado de ello Argentina ha descendido significativamente en los ránkings de corrupción internacionales.

La combinación de, por un lado, un fuerte incremento del consumo masivo (pos crisis) y de la protección social y, por otro, de un aumento de casos de corrupción que tienen una influencia muy limitada en la imagen del gobierno permite abonar la idea de que una mejora en las condiciones de vida de la población no necesariamente tiende a generar ciudadanos más atentos y críticos de la actuación del gobierno sino que puede favorecer todo lo contrario: la impunidad de gobernantes democráticos frente a actos de corrupción (Novaro, 2015: 114).

Capacidades administrativas. Las capacidades administrativas se han ampliado más por la abundancia en la disposición de recursos fiscales que por un mejoramiento en la inteligencia y efectividad con las que actúa el Estado. Al no haber urgencias fiscales disminuyen los incentivos para hacer más eficientes los recursos y capacidades. Existen, sin embargo, algunas excepciones: la evolución de la Agencia Nacional de la Seguridad Social (ANSES), encargada de implementar vastos planes sociales, mostró importantes capacidades para hacer efectivos estos programas en todo el país, sin que sus prestaciones hayan sido objeto de denuncias importantes de corrupción o clientelismo, y asegurando también un alto nivel en la informatización de la información y la atención al público.

La profesionalización y fortalecimiento de la administración pública estuvo lejos de constituir una prioridad de las políticas públicas, y más allá de alguna agencia aislada en la que pueden haberse implementado cambios positivos, no hubo iniciativas relevantes para el conjunto de la administración. De modo que puede interpretarse que la combinación de ingentes recursos fiscales y reducción de la competitividad política resta incentivos a un mejoramiento de las capacidades administrativas.

Probablemente el caso del INDEC haya sido el más notorio, por la ferocidad con la que se partidizó un organismo técnico, por la protesta de los técnicos que allí trabajaban, por la disminución de las capacidades profesionales y por las consecuencias tan visibles de la intervención. Kirchner decidió intervenir este organismo en 2006, una vez que optó por una política económica que privilegiaba maximizar el crecimiento en el corto plazo a costa de elevar sensiblemente los índices de inflación (Novaro, Bonvecchi y Cherny, 2014). Relevó primero a los encargados de medir el Índice de Precios y luego fue reemplazando a todos los funcionarios de mayor rango, que fueron sustituidos por militantes políticos kirchneristas. Desde entonces el INDEC comenzó a difundir un índice de inflación inverosímil, y todos los datos de estadística oficial colectados y publicados por el organismo pasaron a ser de escasa 
credibilidad, destruyendo así una agencia estatal que se había caracterizado por su alto nivel de profesionalismo.

Otras áreas del Estado argentino que tenían también capacidades profesionales con cierta independencia política padecieron el avance de las designaciones partidarias, con la consecuente pérdida de independencia y capacidades administrativas (Scherlis, 2013).

La ausencia de una oposición fuerte capaz de controlar este tipo de acciones, y de hacer pagar un costo al partido gobernante por ellas, facilitó que el gobierno kirchnerista avanzara en esta dirección. De acuerdo a varios estudios desarrollados sobre todo para países postcomunistas, el bajo nivel de competitividad electoral es la variable que mejor explica la partidización y colonización del Estado (O'Dwyer, 2004). El caso argentino en la última década parece confirmar las conclusiones de aquellos estudios.

La disponibilidad de mayores recursos fiscales, volcados en parte a la distribución de planes sociales instrumentados desde el Estado con el auspicioso efecto de reducir la pobreza extrema y limitar así las desigualdades, puede haber implicado también un bajo incentivo para mejorar las capacidades administrativas.

\section{b) Accountability electoral}

En contraste con la desafección y el rechazo social evidenciados en las elecciones de 2001, cuando los votos anulados y blancos sumaron más del 30\%, las elecciones desde 2003 en adelante mostraron una recuperación de la legitimidad perdida, con altos porcentajes de votantes y sumas marginales para los votos en blanco (no mayores al 3\%). El mejoramiento de las condiciones de vida puede haber contribuido a cambiar apatía por opción electoral en sectores de la ciudadanía que se habían alejado de la política a finales de la década de 1990.

Pero por otra parte, cabe presumir que el mejoramiento en la igualdad y el bajo nivel de competitividad han permitido al partido de gobierno "inclinar la cancha" electoral por medio del uso masivo de recursos públicos para la campaña, e incluso modificando reglas electorales. Ha habido permanentes cambios de la legislación electoral, y se han instrumentado prácticas que generaron fuertes tensiones en la interpretación de esta legislación. En el año 2009 la mayoría oficialista en el Congreso decidió el adelantamiento de las elecciones legislativas nacionales, suspendiendo así la vigencia de otra ley también propuesta por el gobierno de Néstor Kirchner en 2005 para establecer una fecha electoral cierta. En ambos casos la decisión estuvo guiada por motivaciones de puro cálculo electoral (Scherlis, 2011). El gobierno de Cristina Kirchner promovió en
2009 que dirigentes con cargos ejecutivos encabezaran las listas de candidatos a cargos legislativos, aun cuando no tuvieran voluntad de asumir esos cargos (estas candidaturas se conocieron popularmente como "testimoniales"). El gobernador de la provincia de Buenos Aires participó de la lista del oficialismo. Tanto el gobierno de Néstor como el de Cristina Kirchner impulsaron al menos una reforma electoral por cada elección, y aunque éstas no alteraron lo esencial del régimen político, siempre se hicieron para dotar de mayores ventajas al partido de gobierno. Si bien el bajo nivel de competitividad política no alentó impugnaciones electorales ni denuncias de fraude facilitó al partido gobernante modificar reiteradamente las reglas electorales adaptándolas a sus estrategias político-electorales de corto plazo.

El aumento en los niveles de igualdad presumiblemente contribuyó también para que las presidencias kirchneristas pudieran incrementar sensiblemente el uso de recursos estatales con fines partidistas. La ampliación de la política social ha provisto a los gobiernos kirchneristas un atractivo significativo en vastos sectores populares, que no parecen rechazar el hecho de que se identifiquen a las estructuras estatales que ofrecen los beneficios con las del partido de gobierno (lo cual involucra desde la simbología desplegada hasta el personal involucrado). Según estudios independientes esto ha contribuido a generar un efecto de "cancha inclinada" que beneficia sobre todo a quienes gobiernan en las provincias (Schiumerini y Page, 2012).

De igual modo, las mejoras en los indicadores de igualdad y la baja competitividad permitieron al kirchnerismo avanzar sobre el sistema de medios de comunicación hostigando a quienes tuvieron posiciones críticas, y estimulando desde el Estado la creación de medios afines al partido de gobierno. La baja competitividad impidió a la oposición evitar -pese a sus reiteradas críticas sobre este tema- que se incrementara sustancialmente el presupuesto para "publicidad oficial", de modo que fue los gobiernos kirchneristas pudieron utilizarlo para hacer propaganda en favor de las principales figuras y candidatos del oficialismo (Ferreira Rubio, 2012: 112).

Libertad de organización partidaria. Si bien es cierto que los individuos son libres para organizarse en partidos políticos, y éstos no son hostigados ni perseguidos, existiendo partidos de las más diversas orientaciones $^{7}$, la mayoría que ha ostentado el Partido Justicialista en el Poder Legislativo ha conseguido modificar sin acuerdo de otros partidos relevantes la ley de partidos, imponiendo requisitos más elevados para obtener el registro partidario y para competir en elecciones. De todos modos, y aunque algunos partidos pequeños calificaron a la reforma de "proscriptiva", ésta se atiene

7 En el año 2009 la Corte Suprema negó la personería al minúsculo Partido Nuevo Triunfo, de manifiesta inspiración nazi, siendo el único caso en las últimas décadas en las que se niega la personería de un partido en razón de sus ideas y programas. 
Tabla 15: Impacto de la competitividad política y la igualdad sobre la accountability electoral

\begin{tabular}{|c|c|c|}
\hline Positivo & Neutral & Negativo \\
\hline \multicolumn{2}{|c|}{ Alta participación electoral (I) } & $\begin{array}{l}\text { Control de los medios de comunicación y } \\
\text { publicidad oficial (C) } \\
\text { Uso masivo y discrecional de recursos estatales } \\
\text { en beneficio del partido de gobierno (C) (I) }\end{array}$ \\
\hline \multirow[t]{2}{*}{$\begin{array}{l}\text { Acceso más equitativo a los medios } \\
\text { audiovisuales durante las campañas }(C)\end{array}$} & $\begin{array}{l}\text { Mayores requisitos para } \\
\text { presentar candidatos }(C)\end{array}$ & \\
\hline & & $\begin{array}{l}\text { Cooptación de opositores }(C) \\
\text { Inestabilidad y poca presencia de alternativas } \\
\text { políticas }(C)\end{array}$ \\
\hline
\end{tabular}

(C) Corresponde a una subdimensión influenciada por la competitividad política

(I) Corresponde a una subdimensión influenciada por la igualdad

en general a los parámetros del derecho comparado latinoamericano y no parece ser un obstáculo irrazonable a la formación de organizaciones partidarias.

\section{Presencia y estabilidad de alternativas políticas.}

La preeminencia del PJ a lo largo de la década contrasta con la inestabilidad y poca presencia de alternativas partidarias en la oposición. Como antes se señaló, el sistema partidario adquirió desde 2003 un carácter de tipo de partido predominante, con el PJ transformándose en el único partido que se mantiene competitivo en el nivel nacional y en cada uno de los distritos provinciales.

¿Puede decirse que la satisfacción de la población con los resultados de la política económica de los primeros años del kirchnerismo conspiró contra la institucionalización de una oposición partidaria consistente? Si bien la literatura sugiere que la igualdad debería tener un impacto positivo sobre la calidad de la competitividad política (Morlino, 2009), luego del derrumbe político del gobierno de la UCR que ocasionó el colapso económico de 2001, hasta 2013 la oposición no había logrado reconstituirse. Los récords de crecimiento económico, ocupación laboral y reducción de pobreza que consiguió el kirchnerismo conspiraron también contra ello. Tampoco logró reunir consenso alrededor de la crítica a los importantes déficits en materia de calidad institucional (incluyendo altos niveles de corrupción) de los gobiernos kirchneristas.

La fortaleza política del kirchnerismo fue aprovechada deliberadamente por sus líderes para limitar y dificultar la presencia y estabilidad de alternativas políticas. Desde la cúspide del Poder Ejecutivo se intentó desarticular a la oposición política por medio de la cooptación de fragmentos de partidos opositores. Como se mencionó oportunamente, los partidos no padecieron persecuciones, su libertad de asociación estuvo garantizada, y contaron con financiamiento público y acceso a los medios de comunicación. Pero en cambio existió una decisión de cooptar a líderes de diferentes partidos opositores. En primer lugar, esto ocurrió con casi todos los gobernadores provinciales elegidos por partidos opositores. La endeblez fiscal de los Estados provinciales y su dependencia de las transferencias que discrecionalmente decide el Poder Ejecutivo nacional, sumados a la debilidad de sus propios partidos, llevaron a estos gobernadores a alinearse con el gobierno nacional. De este modo la UCR, históricamente principal partido de oposición, sufrió la cooptación entre 2003 y 2007 de seis de sus siete gobernadores provinciales, quienes pasaron a formar parte de la coalición oficialista. Lo mismo ocurrió con líderes de otros partidos, a quienes se ofreció el control de algunas oficinas públicas. En ningún caso el gobierno intentó llegar a un acuerdo de coalición entre partidos, sino que en todos los casos se trató de acuerdos puntuales con líderes (o facciones partidarias) en forma particularizada, valiéndose para ello de ofrecimientos de cargos o recursos públicos. De modo que la ausencia de competitividad sirvió también como escenario propicio para que los gobernantes kirchneristas intentaran restringir aún más la presencia de alternativas políticas.

Paralelamente, mientras el PJ permanece como el único partido efectivamente competitivo a nivel nacional, también es cierto que el peronismo no es un partido monolítico, y que genera alternativas a su propio liderazgo. De modo que la baja competitividad interpartidaria fue en alguna medida compensada por la disputa entre diferentes facciones peronistas. Dado su dominio del sistema político, el peronismo pasó a dirimir sus conflictos internos por medio de las elecciones generales. Así, en las elecciones presidenciales de 2011 la suma de tres candidaturas peronistas alcanzó el $68 \%$ de los votos a nivel nacional, y en las elecciones legislativas de 2013 en la Provincia de Buenos Aires cuatro listas peronistas reunieron el $83,2 \%$ de los votos, triunfando en este caso Sergio 
Massa, peronista antes kirchnerista pero devenido para esta instancia en opositor.

Ocurre que el reemplazo de la competitividad interpartidaria por una competitividad alternativa, intra-partidaria, entre facciones del peronismo, tiene varios problemas importantes en términos de calidad democrática. En términos de accountability electoral, se ha destacado que el peronismo tiene una enorme flexibilidad para mostrar diferentes posiciones programáticas según el momento histórico. Pero el costo evidente de esta flexibilidad del peronismo reside en que es dificil para los votantes argentinos valerse de las etiquetas partidarias para decidir su voto premiando o penalizando a sus gobernantes. Si el peronismo puede ser el motor de las reformas de mercado entre 1989 y 1999 y también su antítesis, el baluarte de la intervención estatal, entre 2003 y 2015, entonces las etiquetas partidarias no cumplen con una de las funciones que clásicamente les adjudica la teoría democrática, como es la de facilitar la rendición de cuentas electoral. Además, esta pluralidad de liderazgos peronistas no suele resolver sus conflictos mediante una competencia libre y limpia. La tramitación del liderazgo peronista suele en cambio darse en forma convulsionada. Los conflictos internos del peronismo son en general trasladados a toda la sociedad, pero para ello las reglas electorales suelen entrar en tensión. En resumen, aunque el peronismo respeta la regla de la mayoría, suele manipular el resto de las reglas institucionales más de lo que se somete a ellas. Así, la inestabilidad institucional, característica esencial de la democracia argentina (Levitsky y Murillo, 2005), se ha incrementado con el resultado de una mayor debilidad en la presencia y estabilidad de alternativas políticas.

\section{c) Accountability interinstitucional}

Relaciones Ejecutivo-Legislativo. La baja competitividad política afectó también el vínculo entre la Presidencia y las cámaras parlamentarias. Hubo dos tipos de relaciones, ambas caracterizadas por la ausencia de colaboración entre gobierno y oposición. Entre 2005 y 2009 y entre 2011 y 2013, el dominio del PJ supuso un desequilibrio de poderes entre el Ejecutivo y el Legislativo a favor del primero. El período 2003-2005 también estuvo signado por el dominio del peronismo pero la falta de cohesión en los comienzos del kirchnerismo (con la pelea interna entre Néstor Kirchner y Eduardo Duhalde) limitó la eficacia legislativa de la Presidencia, mientras que entre 2009 y 2011 el partido de gobierno perdió la mayoría en la Cámara de Diputados. Sin embargo, el resultado no fue la colaboración sino el veto mutuo de iniciativas entre gobierno y oposición.
De todos modos, vale destacar que el Poder Ejecutivo logró apoyo de otros partidos en el Congreso para sancionar leyes relevantes (como la estatización del sistema previsional y la de la petrolera YPF, igual que la así llamada "Ley de Medios"). En los casos en los que no logró obtener la mayoría parlamentaria necesaria, el gobierno admitió la derrota y respetó la decisión del Poder Legislativo. El ejemplo más relevante en este sentido se dio durante 2008, en lo que se dio el llamado "conflicto del campo": un aumento de impuestos resistido por los productores agropecuarios generó un conflicto con alto voltaje político, que terminó siendo definido en contra de la propuesta del gobierno por un solo voto en el Senado. ${ }^{8}$

Corte Suprema. Como ya mencionado, la independencia de la Corte Suprema actúa como freno a posibles excesos del poder, pero la decisión de constituir una corte prestigiosa e independiente es anterior a la situación de predominio consolidado del PJ y a los resultados socioeconómicos. Más bien al contrario, la decisión fue tomada por el presidente Néstor Kirchner al poco tiempo de asumir el cargo en 2003 en una situación de debilidad política. En cambio, desde la consolidación del poder kirchnerista, la política hacia el Poder Judicial ha sido de permanente tensión, motivada por los intentos del gobierno por controlar la designación de jueces y sus decisiones.

Ombudsman. El Defensor del Pueblo es designado por el Legislativo. Se trata de una figura que carece de relieve político. Durante los gobiernos kirchneristas este cargo ha estado ocupado por figuras con escaso peso político pertenecientes al Partido Justicialista, aunque no fueran de la propia facción del presidente.

Organismo auditor. Existen dos organismos auditores principales, uno en el ámbito del Poder Ejecutivo (Sindicatura General de la Nación-SIGEN) y otro en el del Legislativo (Auditoría General de la Nación-AGN). La SIGEN, como ya se mencionó, no desarrolla investigaciones serias ni independientes dado que está controlada políticamente por funcionarios leales al presidente. La dirección de la AGN es ocupada por un opositor y ha logrado desarrollar algunas investigaciones independientes. Carece sin embargo de capacidades sancionatorias y sólo puede hacer recomendaciones. En consecuencia, una Presidencia ocupada por un partido dominante no tiene incentivos para tomar en cuenta las recomendaciones del organismo auditor.

Autonomías provinciales. Tal como ya se mencionó, la autonomía de las provincias está condicionada por 
Tabla 16: Impacto de la competitividad política y la igualdad sobre la accountability interinstitucional

\begin{tabular}{|l|l|l|}
\hline \multicolumn{1}{|c|}{ Positivo } & \multicolumn{1}{|c|}{ Neutral } & \multicolumn{1}{c|}{ Negativo } \\
\hline Corte Suprema independiente (C) & & $\begin{array}{l}\text { Mayoría del oficialismo en ambas cámaras y dominio de } \\
\text { las relaciones Ejecutivo-Legislativo (C) }\end{array}$ \\
\hline & & \begin{tabular}{l} 
Ombudsman designado por el Legislativo (C) \\
\hline
\end{tabular} \\
\hline & Auditoría independiente pero con baja incidencia real (C) \\
\hline & $\begin{array}{l}\text { Autonomía provincial muy condicionada por el poder fiscal } \\
\text { de la Presidencia (C) (I) }\end{array}$ \\
\hline
\end{tabular}

(C) Corresponde a una subdimensión influenciada por la competitividad política

(I) Corresponde a una subdimensión influenciada por la igualdad

los recursos fiscales que maneja el Ejecutivo. El poder fiscal de la Presidencia en relación con el de las provincias ha crecido entre 2003 y 2013 de manera notable. Dicho incremento está basado en dos de los ingresos más significativos en términos presupuestarios que no son distribuidos de manera automática a las provincias: las retenciones a las exportaciones de granos y los ingresos previsionales. Esta situación reproduce la dependencia de las provincias respecto al Ejecutivo nacional y permite a la Presidencia reforzar su poder partidario e institucional.

La reducción del grado de competitividad política afectó la autonomía provincial quitando margen de acción a los gobernadores elegidos por partidos distintos al del presidente. Precisamente de estos gobernadores, los elegidos en sus provincias por partidos que en el nivel nacional son opositores al gobierno, cabría esperar una posición de mayor autonomía política. Pero la ausencia de una competencia nacional equilibrada, con la consecuente ausencia de expectativa de que otros partidos distintos al peronista accedan en un futuro mediato a la Presidencia, actúa como un fuerte incentivo para que estos gobernadores defeccionen de la línea política definida por sus organizaciones nacionales para acercarse al gobierno nacional en búsqueda de recursos fiscales. En otros términos, para un gobernador de la UCR podría ser racional no alinearse con el gobierno resignando así algunos recursos fiscales si su partido tuviera la expectativa cierta de acceder a la Presidencia en un futuro próximo. Ante la ausencia de esta expectativa, lo racional para el gobernador de la UCR es alinearse con el presidente peronista en búsqueda de los recursos materiales para su provincia.

Por supuesto, la superabundancia de recursos fiscales concentrados en el Ejecutivo nacional sirvió también para destinar recursos a las provincias y municipios, lo cual sirvió por un lado, como ya se afirmó, para alinear a gobernadores e intendentes, pero también para ganar apoyo electoral masivo, sobre todo en los sectores más pobres. De este modo, asignando recursos directamente a los habitantes de las provincias, el Ejecutivo redujo niveles de pobreza y desigualdad mientras simultáneamente reducía la autonomía de los gobiernos provinciales.

\section{Conclusiones}

Este trabajo se propuso dos objetivos principales. El primero de ellos ha sido analizar la calidad de la democracia en Argentina. Para ello se presentó una descripción sobre datos cuantitativos de la observación de diferentes dimensiones de la calidad de la democracia. Estos datos muestran que la calidad de la democracia en Argentina se ha mantenido relativamente estable, con evidentes mejoras durante los primeros años pos-crisis 2001 y otros de retroceso que se hicieron muy visibles durante el segundo gobierno de Cristina Kirchner.

En segundo término, se propuso un ejercicio consistente en identificar el impacto de la variación en algunas dimensiones de calidad democrática sobre otras. Se seleccionaron para ello dos variables independientes que en la última década tuvieron una variación significativa en Argentina: competitividad política e igualdad. Como es sabido, es dificil establecer relaciones de causalidad entre las dimensiones que hacen a la calidad de la democracia, dado que en términos generales ellas están fuertemente vinculadas entre sí, sin que sea sencillo identificar cuándo un cambio en una de ellas genera el cambio en la otra o viceversa. En este caso optamos por tomar las dos variables con mayor nivel de variación durante la última década, para luego observar qué efectos pudieron tener estas variaciones sobre el resto, de modo que, utilizadas analíticamente como variables independientes, se observó el impacto sobre otras dimensiones.

Por un lado, la reducción en el nivel de competitividad durante el período de estudio política afectó negativamente tres dimensiones de la calidad democrática: accountability electoral, accountability interinstitucional e imperio de la ley. El predominio político del peronismo tanto al nivel del Ejecutivo nacional como en los niveles provinciales y municipales ha sido simultáneo con la retracción y dispersión de los partidos opositores. Ello dio lugar a un sistema político con poderes 
más concentrados y con menor capacidad de control interinstitucional. El Ejecutivo además utilizó su ventaja electoral y el control que ella le otorgó en términos institucionales para generar condiciones que dificultaron la existencia de elecciones plenamente equitativas. Un elemento clave en el período 2003-2013 ha sido la fuerte partidización del aparato estatal y la utilización masiva de recursos estatales para favorecer al partido de gobierno.

Que la reducción del nivel de competitividad atenta contra la calidad democrática es parte del conocimiento establecido en ciencia política. De modo que el vínculo entre baja competitividad política y deterioro del accountability y Estado de derecho en la Argentina entre 2003 y 2013 no resulta sorprendente. En cambio, resulta más llamativo que un mejoramiento de los niveles de igualdad social no impacte positivamente en otras dimensiones de la calidad democrática. La igualdad es habitualmente contemplada como requisito para una democracia de calidad. Como señala Morlino (2009), la libertad y la igualdad están vinculadas a las diferentes formas de accountability y a la responsividad. Este trabajo no pretende negar esta relación. Sin embargo, el período 2003-2013 en argentina muestra que la reducción de las desigualdades sociales y económicas no necesariamente va de la mano de la mejora de la calidad democrática. Esto ocurre cuando las mejoras en la igualdad resultan de una coyuntura económica especialmente favorable que otorga masivos recursos al gobierno para paliar las condiciones de pobreza van acompañadas de prácticas institucionales de baja calidad, con altos niveles de corrupción, escasos controles interinstitucionales, niveles descendentes de competitividad política y reducción de la accountability vertical.

El emblemático programa de Asignación Universal por Hijo ilustra la tensión entre mejoramiento social y reducción de calidad democrática: el gobierno optó crearla a través de un decreto presidencial cuando muchos proyectos similares habían sido promovidos por diversos partidos de la oposición, y la propuesta habría sido fácilmente aprobada como ley por el Congreso. Desde entonces el Ejecutivo puede decidir a discreción cuándo y cuánto actualizar el monto de esta prestación. De modo que el beneficio recibido por millones de personas pobres y que constituye una ayuda muy significativa para poder acceder a bienes y servicios básicos, es percibido como resultado de la voluntad presidencial, y no como un derecho adquirido a partir de la sanción de una ley. En definitiva, experiencias como la argentina permiten poner en cuestión la relación entre diferentes dimensiones de la calidad democrática y podrían llevarnos a asumir que el vínculo entre ellas puede depender de las condiciones contextuales en las que se desarrollan.

Vale aclarar de todos modos que las mejoras en la igualdad que estamos aquí evaluando no suponen una modificación estructural en la sociedad argentina, sino simplemente una reducción de algunos puntos del coeficiente Gini a partir de niveles de enorme desigualdad alcanzados hacia finales de la década de 1990. Los niveles alcanzados hacia finales de 2013 son equivalentes a la de comienzos de esa misma década.

Podemos concluir entonces que durante el período 2003-2013 ha habido una simultánea reducción de la competitividad política y mejoramiento relativo en los niveles de igualdad social. El primero de estos factores generó a su vez mayor concentración de poderes y menores controles y apego al Estado de derecho. El mejoramiento de la igualdad social en cambio no tuvo los efectos que la teoría normalmente espera en términos de mejorar la participación, la rendición de cuentas, la responsividad y la libertad.

Por otro lado, tampoco es sencillo adjudicar al aumento en la igualdad un impacto negativo directo en el empeoramiento de otras dimensiones, pero en cambio sí, a partir del modo en el que se instrumentaron las políticas de mejoramiento de las condiciones sociales, es posible sugerir que mejoras en la igualdad pueden haber posibilitado el declive en dimensiones tales como accountability vertical y Estado de derecho.

Argentina, no obstante, es una democracia en que los principios fundamentales de la regla de la mayoría y de la protección de los derechos individuales son esencialmente respetados. La reducción de la competitividad política no llevó a limitar las libertades individuales ni las libertades asociativas. Los individuos se manifiestan libremente, las organizaciones sociales y sindicales tienen pleno derecho a la movilización y protesta, y si bien la prensa independiente fue duramente hostigada durante la segunda parte del período, ha conservado la libertad editorial para difundir noticias y opiniones. Finalmente, la ciudadanía a través de las elecciones legislativas de 2013 se ha constituido como un límite para las aspiraciones hegemónicas del kirchnerismo. Todos estos factores hacen prever que la competitividad pueda ser recobrada. De modo que cabe esperar que otras dimensiones puedan también mejorar consecuentemente.

\section{Referencias}

BERTRANOU,Fabio;CETRÁNGOLO, Oscar;GRUSHKA, Carlos; CASANOVA, Luis. Beyond the privatisation and re-nationalisation of the Argentine pension system: coverage, frag- mentation, and sustainability. SSRN Scholarly Paper ID 2191202. Rochester, NY: Social Science Research Network, 2012.

CALVO, Ernesto. Legislator success in fragmented congresses in 
Argentina. Cambridge: Cambridge University Press, 2014. CRUCES, Guillermo; GASPARINI, Leonardo. Desigualdad en Argentina. Una revisión de la evidencia empírica: primera parte. Desarrollo Económico, v. 48, n. 192, p. 395-437, 2009.

. Las asignaciones universales por hijo en Argentina: impacto, discusión y alternativas. Económica, v. 56, n. 1, p. 105146,2010

FERREIRA RUBIO, Delia. Financiamiento de los partidos políticos en Argentina: modelo 2012. Revista Elecciones, v. 11, n. 12, p. 99-122, 2012.

GALASSO, Emanuela; RAVALLION, Martin. Protección social en la crisis: el Plan Jefas y Jefes de Hogar en Argentina. Washington: Grupo de Investigación sobre Desarrollo, Banco Mundial, 2003.

GARRIDO, Manuel. La situación actual de los jueces subrogantes en el ámbito federal. Documento de Trabajo $N^{\circ} 43$. Buenos Aires: CIPPEC, 2010.

LEVITSKY, Steven. La transformación del justicialismo. Del partido sindical al partido clientelista, 1983-1999. Buenos Aires: Siglo XXI Editora, 2005.

LEVITSKY, Steven; MURILLO, María Victoria. Argentine democracy: the politics of institutional weakness. Pennsylvania: Pennsylvania State University Press, 2005.

MORLINO, Leonardo. Explicar la calidad democrática: ¿qué tan relevantes son las tradiciones autoritarias? Revista de Ciencia Política, v. 27, n. 2, p. 3-22, 2007.

.Qualities of democracy: how to analyze them. Aberdeen: Centre for the Study of Public Policy, University of Aberdeen, 2009.

Changes for democracy: actors, structures, processes. Oxford:
Oxford University Press, 2011.

NOVARO, Marcos. Informe sobre la calidad de la democracia en Argentina. Buenos Aires: Red de Estudios sobre la Calidad de la Democracia en América Latina, 2010.

Manual del votante perplejo. Buenos Aires: Katz Editores, 2015

NOVARO, Marcos; BONVECCHI, Alejandro; CHERNY, Nicolás. Los límites de la voluntad. Buenos Aires: Ariel, 2014.

O'DWYER, Conon. Runaway State building. World Politics, v. 56, p. 520-553, 2004.

REPETTO, Fabián; DAL MASETTO, Fernanda Potenza. Protección social en la Argentina. Santiago: División de Desarrollo Social, CEPAL, 2011.

SCHERLIS, Gerardo. El kirchnerismo y las reglas de la competencia electoral: decisiones cruciales en la construcción de un proyecto político. En MALAMUD, Andrés; DE LUCA, Miguel (comps.). La política en los años de los Kirchner. Buenos Aires: Eudeba, 2011.

_. The contours of party patronage in Argentina. Latin American Research Review, v. 48, n. 3, p. 63-84, 2013.

SCHIUMERINI, Luis; PAGE, María. El efecto "cancha inclinada": ventajas del oficialismo en la política de las provincias argentinas. Documento de políticas públicas 115. Buenos Aires: CIPPEC, 2012

TORRE, Juan Carlos. El peronismo como solución y como problema. En NOVARO, Marcos (ed.). Entre el abismo y la ilusión. Peronismo, democracia y mercado. Buenos Aires: Norma, 1999. ZANATTA, Loris. El populismo, entre religión y política. Sobre las raíces históricas del antiliberalismo en América Latina. Revista EIAL, v. 19, n. 2, 2008.

\title{
The impact of political competitiveness and equality in the quality of democracy. The Argentinian case (2003-2013)
}

\begin{abstract}
:
The purpose of the paper is to analyze the quality of democracy in Argentina in the period 2003-2013. First of all, we describe the evolution of several typical indicators of democratic quality. The second part looks at the impact of the variation in political competitiveness and equality on three dimensions: rule of law, electoral accountability and interinstitutional accountability. The results are consistent with the literature which argues that a reduction in competitiveness negatively affects the quality of democracy. And they suggest that an improvement in the equality indicators, under certain circumstances, could favor the deterioration of the quality of democracy.
\end{abstract}

Key words: Argentina; kirchnerismo; quality of democracy; competitiveness; equality; accountability.

\section{O impacto da competitividade política e da igualdade na qualidade da democracia. 0 caso argentino (2003-2013)}

\section{Resumo:}

O objetivo do trabalho é analisar a qualidade da democracia na Argentina no período 2003-2013. Em primeiro lugar, descrevemos a evolução dos diferentes indicadores típicos de qualidade democrática. A segunda parte observa o impacto da variação na competição política e 
na igualdade sobre três dimensões: Estado de direito, accountability eleitoral e accountability interinstitucional. Os resultados são consistentes com a literatura que argumenta que uma redução da competitividade afeta negativamente a qualidade da democracia. E sugerem que a melhoria dos indicadores de igualdade, sob determinadas circunstâncias, poderia favorecer a deterioração da qualidade democrática.

Palavras-chave: Argentina; kirchnerismo; qualidade democrática; competitividade; igualdade; accountability. 